of the nerves arising therefrom. Lastly, Faradisation is useless in the general paralysis of the insane; injurious in myelitis until after recovery has taken place; and is the only remedy worthy of confidence in the fatty atrophy of muscles, and in the paralysée atrophique graisseuse de l'enfance. As strikingly illustrative of the charming results sometimes obtained by its judicious employment, I will, in conclusion, quote the following case which I treated when in practice in Liverpool, and which was subsequently published in Mr. Lobb's work on galvanism.

CASE. A. B., aged 18, a single gentleman, came under my care to be treated for an attack of paraplegia, on August 27th, 1859. He was a fresh looking well developed young man of sanguine temperament. The vascular and respiratory organs appeared healthy, and the functions of the abdominal viscera were well performed. The pulse was 80 , regular; the skin was cool; the tongue was furred, moist, and steadily protruded; there was no defect of articulation. For some time past, be had been complaining of gradually increasing debility of the lower limbs; and latterly they had been utterly useless as organs of locomotion. He was quite unable to stand, and moved from one apartment to another by the aid of a pair of crutches. If he attempted to rise from a sitting posture by grasping a chair or table, he fell back quite helpless; if supported on one side, the legs doubled up, the knees knocking together; and, if not prevented, he would sink to the ground. He had no pain in the back, and no pain was felt on percussion along the spine. Sleep was natural, not troubled with dreams or involuntary startings; the senses and sensibility were normal. There was no evidence of saturnine poisoning, of worms, nor of rheumatic affection. The functions of the bladder and rectum were normal; and the superior extremities were unaffected. He had been taking eleven grains of sulphate of zinc daily, which was prescribed by the late Dr. Bright. Two sisters were afflicted much in the same way to a greater degree; one having being confined almost constantly in the recum. bent posture for eleven years.

August 27th, 1859. A gentle to-and-fro galvanic current was passed from the lumbar region to the feet, and electricity localised in each of the affected muscles for one or two minutes.

August 30th. He complained of lassitude after the last séance ; but expressed himself now as slightly im. proved. The localised electricity was again applied.

September 1st. He was able to put down his crutches and walk across the room to meet me to-day. He stated that since the last operation he had put his foot in the stirrup and mounted a horse unassisted. The electricity was repeated.

Sept. 3rd. Owing to indisposition, I was unable to attend to-day, according to appointment; but received a note from the patient's inother, stating that the crutches were quite discarded, and that he was so well as scarcely to need further help.

Sept. 4 th. The patient attended church to.day, walking there and back, about a quarter of a mile, and standing during service.

Sept. 5th. He could walk steadily at a good pace. $\mathrm{He}$ expressed himself as quite recovered. The electricity was repeated.

Sept. 7th. He stated he could run and jump as well as any body; he appeared quite well. The electricity was repeated.

The following remarks were appended to this case. "The effect of the galvanic current in the foregoing case was marvellous; and to witness the delight with which the patient noticed the rapid and decided improvement, was truly gratifying. Completely crippled himself, and with the melancholy spectacle before his eyes of two paralysed sisters, whose cases had resisted all treatment, no wonder that it was with but little faith that he resorted to galvanism as a dernier espoir. So slight was his hope of benefit, that had not the improvement been as rapid as it was marked, I feel that he could not have been induced to continue the application. The integrity of the electro-muscular contractility, and the absence of any decided indications of head-affection, excluding the diagnosis of cerebral or spinal lesion, warranted a very sanguine prognosis, and thus enabled me to offer him sufficient inducement to commence the treatment.

6: The current passed from the lumbar region to the feet was merely a placebo; and I attributed the cure entirely to the localisation of the electricity in each of the affected muscles."

I met the patient some two years afterwards at the seaside quite well, and believe he has since continued in perfect health.

\section{ON MALGAIGNE'S HOOKS FOR FRACTURED PATELLA.}

By Campenel De Morgan, F.R.S., Surgeon to the Middlesex Hospital.

IN a recent number of one of the medical journals, $M$. Malgaigne's hooks for the treatment of fractured patella are classed amongst the fracture apparatus which " may be regarded as models of what ought not to be used."

At the Middlesex Hospital, a large number of cases have been treated by the application of these hooks-perhaps, in no English hospital have they been more fiequently used-and the results have been very satisfactory. My colleague, Mr. Henry, called attention to some cases under his care, in which a very close, and probably a bony, union had taken place under treatment by this apparatus.

The instrument consists of a pair of iron plates, each furnished at one end with two double sharp pointed hooks. One pair of these hooks is thrust through the skin, and is made to catch upon the upper edge of the bone; the other is similarly thrust in till it catches the lower edge. A screw bar then unites the two pieces; and by turning this the separated portions of bone can be readily brought into contact. When once fixed the hooks are allowed to remain until the parts have united; or until it may be thought desirable to replace them by a starched bandage.

Now, this sounds like a painful and somewhat savage proceeding, and one likely to be attended with danger; whether, in ordinary cases of fractured patella, and when cautiously applied, the hooks can give rise to mischievous consequences, I do not know. I have never seen the least indication of such results; and should not an. ticipate their occurrence. But as to the extremely small amount of pain which their application produces, and to its almost entire, und often entire, absence during the time they are worn, I can speak very positively'; so far as the cases which I have seen or treated are concerned.

A case occurred not long since in the hospital, which illustrates this very satisfuctorily. A woman slipped in coming down stairs, and fractured both patellæ. There was for three days a good deal of effusiou into the joints. When this had subsided, I applied the hooks to the one side, leaving the other without any apparatus at all; both legs were raised in the usual position. Pain was, of course, produced, but only to a slight extent, while the hooks were being thrust through the skin. When I saw her the next day, she had not more pain on the one side than on the other; in fact, she bad no pain on either side. The hooks remained on for more than a month without producing the least irritation or uneasiness. The broken portions of bone were pretty closely approximated on the side to which the hooks had been 
applied; on the opposite side, there was an average amount of separation-from half to three quarters of an inch.

Those who are conversant with the fact of the freedom from irritation which characterises the presence of metallic sutures in the skin, would be prepared to expect a similar immunity from the presence of those hooks, if the parts be kept from motion.

I have a case now in the hospital which shows very markedly the simplicity of this plan of treatment, as well as the little tendency to irritation which it causes. A woman was brought in with a fractured patella. She was far advanced in pregnancy; and the house-surgeon judged very properly that she would be, in her condition, extremely discomforted if the limb were placed in the ordinary elevated position. He left her, therefore, till my visit. I found that there was only a moderate amount of swelling; and that the two fragments of bone were about an inch asunder. The hooks were at once applied, and the two pieces of the patella brought into contact. No splint or roller was used; nor was the limb elevated; she was simply enjoined to remain as quiet as she could. She has been lying perfectly comfortable, with no irritation around the hooks, and no pain unless they be moved about. They have now been on for about a month; and the fracture seems to be rearly united.

There is one inconvenience which sometimes occurs, and which it requires a little management to overcome. The bones have a tendency to meet at an angle; so that while the two lower edges, for example, may be in con. tact with one another, the two upper edges may be separated by an eighth of an inch. I do not know whether practically there is any great harm in this; probably, the union is not so firm as it would be if the whole surfaces were in contact. The difficulty may generally be overcome by an alteration in the direction of the hooks, especially of the upper ones. They may be made to catch the bone in a different manner, without being altogether withdrawn; so that the pain of a second perforation of the skin is avoided. When once the proper position is obtained, and the screw adjusted, no further interference may be requisite until it is thought proper to remove the instrument.

So far from regarding these books as " models of what ought not to be used", my belief is that, if due caution be observed, there is no method of treatment which, with so little trouble to the surgeon, or irksomeness and pain to the patient, will produce such satisfactory results.

Homeopathic Discussions in Congress. In the Halls of Congress the important question of life's value in the army, and conversely, the physician's value, as the conservator of life and health, are being earnestly discussed. Homœopathy paraded its pretentious claims, backed by some 35,000 petitioners; but impressed by some proper sense of public responsibility, both houses of Congress declined to recommend the hallucinations of Hahnemann to the army. And for the gratification of our readers, the fact may here be stated that we have just been shown a neatly printed copy of our leading editorial of January 1Sth, "Homcopathy in Military Hospitals," which we are informed was ordered, printed and placed in the hands of every Member of Congress at the expense of a few public.spirited gentlemen, the very day that number of our Journal was received at Washington. Such unanswerable testimony of facts contributed its humble share towards saving the army from the pressure of the host of homœopathic quacks who were just then uttering their bugbear boasts that General McClellan's life had been saved by hourly prescriptions by telcgraph from the office of the prince of charlatans in New York. (American Medlical Times.)

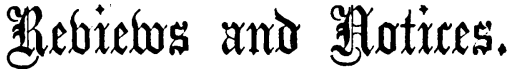

A Cinical Treatise on Diseases of the Livero By Dr. Fried. Theod. Frerichs, Professor of Clinical Medicine in the University of Berlin $\mathbb{\infty}$ etc. Translated by Charles Murchison, M.D. F.R.C.P., Physician to the London Fever Hospi-es tal, etc. In Two Volumes. Vol. I, pp. 402. Vol $\vec{\circ}$ II, pp. 584. The New Sydenham Society. London:1860 and 1861.

ThE Council of the New Sydenham Society have done well in issuing an English translation of Dr. Frerichs's work on the Liver; for it is one of those books which, independently of the character. impressed on them by the reputation of the author, $\omega$ are most interesting in the present age of medicine. Or As we have already observed in a former number, $\vec{\omega}$ the author seeks to point out, in relation to theo liver, the bearings of scientific observation on clinical practice.

The first volume contains nine chapters, arranged 3 under the following heads:-1. Historical Introduction ; 2. Relative Size and Weight of the Liverin Health and Disease; 3. Sketch of the Relative Sizes and Forms of the Liver in its Morbid Condi-? tions, and of their Diagnostic Value ; 4. Jaundice; 5. Suppression of the Functions of the LiverAcholia and its Consequences; 6 . Chronic Atrophy of the Liver; 7. The Fatty Liver; 8 . The Pigmento Liver ; 9. Hyperæmia of the Liver and its Consequences. There is also an Appendix of Observations $\stackrel{\mathbb{D}}{\mathbb{D}}$ and Experiments, in support of statements made in $\vec{F}$ the body of the work.

It would be impossible for us to give such an 3 analysis of each chapter of the work as its character warrants ; and this is, perhaps, the less necessary, as many of our readers are members of the New Sydenham Society. We shall, therefore, confine ourselves to the selection of those portions which appear to us to contain what is most noteworthy, and 윽 shall endeavour to describe, in as concise a form as 3 . is consistent with clearness, some of the principal views on hepatic diseases which are held by the learned author.

Proceeding on this plan, we first take up the $\frac{}{2}$ fourth chapter, which is on Jaundice. On the pro- N duction of the disease, two principal theories have $D$ been held : the one being, that jaundice arises in a disturbance of the functions of the liver-of the secretion or excretion of bile; the other, that, under $N$ certain conditions, substances resembling the ingre- N dients of bile are formed in the blood independently $O$ of the liver. Dr. Frerichs holds, in contradistinction to a view that has been very commonly entertained, that bile does not preexist in the blood, but that it $\mathbb{D}$ and sugar are formed in the liver as products of cell- ? growth ; and he believes that most, if not all, cases 7 of jaundice are produced by the reabsorption of bile $\overline{0}$ already secreted. The question then is, to discover $\mathbb{\mathbb { D }}$ the causes preventing the escape of bile from the $\frac{?}{\mathbb{D}}$ liver, or producing its flow into the blood. It is $\stackrel{\mathbb{Q}}{\varrho}$ only when no such causes can be ascertained-as in pyæmia, some forms of intoxication, fevers, mental emotion, etc. - that he would admit, as a provisional 8 hypothesis, the origin of the icteric condition in the blood itself.

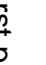

